\title{
Non-Invasive Winding Fault Detection for Induction Machines Based on Stray Flux Magnetic Sensors
}

\author{
Zheng Liu ${ }^{1}$, Wenping Cao ${ }^{2,3}$, Po-Hsu Huang ${ }^{3}$, Gui-Yun Tian ${ }^{1}$, James L. Kirtley ${ }^{3}$
}

1: School of Electrical and Electronic Engineering, Newcastle University, Newcastle Upon Tyne, U.K.

2: School of Engineering and Applied Science, Aston University, Birmingham, U.K. w.p.cao@ aston.ac.uk

3: Department of Electrical Engineering and Computer Science, Massachusetts Institute of Technology, U.S.A.

\begin{abstract}
Non-intrusive monitoring of health state of induction machines within industrial process and harsh environments poses a technical challenge. In the field, winding failures are a major fault accounting for over $\mathbf{4 5 \%}$ of total machine failures. In the literature, many condition monitoring techniques based on different failure mechanisms and fault indicators have been developed where the machine current signature analysis (MCSA) is a very popular and effective method at this stage. However, it is extremely difficult to distinguish different types of failures and hard to obtain local information if a non-intrusive method is adopted. Typically, some sensors need to be installed inside the machines for collecting key information, which leads to disruption to the machine operation and additional costs. This paper presents a new non-invasive monitoring method based on GMRs to measure stray flux leaked from the machines. It is focused on the influence of potential winding failures on the stray magnetic flux in induction machines. Finite element analysis and experimental tests on a $1.5-\mathrm{kW}$ machine are presented to validate the proposed method. With time-frequency spectrogram analysis, it is proven to be effective to detect several winding faults by referencing stray flux information. The novelty lies in the implement of GMR sensing and analysis of machine faults.
\end{abstract}

Index Terms-- induction machine, stray flux, winding failures, condition monitoring

\section{INTRODUCTION}

Induction machines play an essential role in industrial drives and wind power generation worldwide. They are found in use in motor drive systems from few watts to several megawatts [1]. To ensure the reliable operation and long lifetime of these machines, condition monitoring technologies have been developed to detect the occurred faults and to predict impending failures.

Stator winding faults have been reported as one major failure in induction machines [2]. Once a winding short circuit occurs in the machine, a large current will flow in the shorted turn or coil and generate excessive heat. If left untreated, this could build up to break down the insulators and propagate the fault to the adjacent coils or even lead to a complete machine failure. Moreover, phase to ground and phase to phase

This work is supported by the FP7 under FP7-PEOPLE-2013-IOF (\#627270) and FP7-PEOPLE-2012-IRSES (\#318925). winding faults can also damage the core. In this circumstance, it is essential to monitoring the condition of stator windings and distinguish different electrical winding faults to aid in decision making as well as reduce operational and maintenance costs.

In the previous researches, various methods are reported for monitoring and detecting the winding failures in induction machines. Several parameters have been identified as indicators of winding faults. Among these technologies, current spectrum analysis is the most widely used at this moment, which is based on referencing certain harmonic components to correlate health state of stator windings [3]. However, current signature analysis requires installing sensors in the winding coils while some of these locations are hard to access [4]. Meanwhile, motor current signature analysis has a common drawback - the results are easily influenced by other failures and unbalance situations. This disadvantage will reduce the sensitivity and accuracy of tracking incipient failures [5]. Additionally, current parameters cannot provide local information which is essential to further maintenance.

In this case, developing a non-invasive approach with easy implement and reliable detection has become important. Several technologies are developed to capture the stray magnetic flux [6]-[8]. Stray flux of induction machines is the flux escaped from the yoke and housing, and directly reflects health state of motors. Stray flux monitoring technologies can also provide comprehensive and globe information of the induction machines, in addition to location information.

Generally, search coils are widely used to obtain the flux (main or stray) in a coil loop. However, these are impedance coils and suffer from low sensitivity at low speeds and nonlinearity at high supply frequencies [5]. This work uses giant magnetoresistive (GMR) sensors for measuring stray flux in induction machines. These are small inexpensive sensors and can measure magnetic field at a point and to a high accuracy. In particular, its wide frequency response can help identify different types of winding failures in induction machines. By referencing time-frequency spectrogram of stray flux signals, winding failures can be observed combining with time information together. Comparison with traditional FFT, 
spectrogram also provides harmonics patterns to illustrate health state of machines.

\section{EXISTING TECHNIQUES}

In order to detect faults within the induction machines, it is essential to understand different types of failures in industry and existing condition monitoring technologies based on stray magnetic flux.

\section{A. Induction Machine Failures}

Induction machines typically operate at harsh environment which leads to approximately $6 \%$ failure rate each year [9]. The faulty induction machines may cause whole drive systems to shut down or even catastrophic damage. Among these failure machines, several surveys have investigated and illustrated the detailed failure types and rates [10]. The common failures of induction machines include stator winding faults, bearing faults, rotor bar/ring faults and shaft failures. Stator winding fault is one of the most frequent failures in the drive system. Fig 1 shows the failures rate of typical motor drive applications. Without a doubt, it is important to develop reliable and accurate condition monitoring systems to safeguard the machine operation. In this paper, the focus is placed on stator winding short-circuit failures.

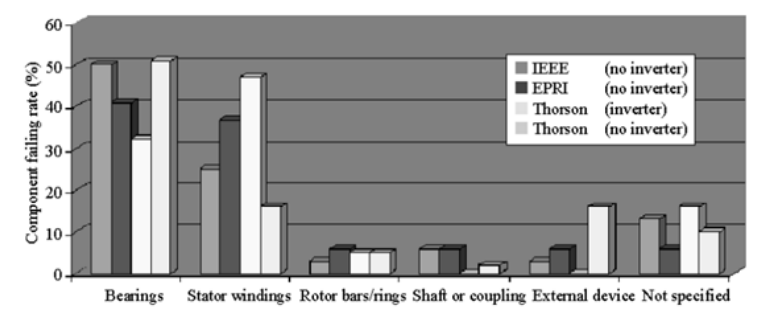

Fig. 1. Induction motor component failure rate [11]

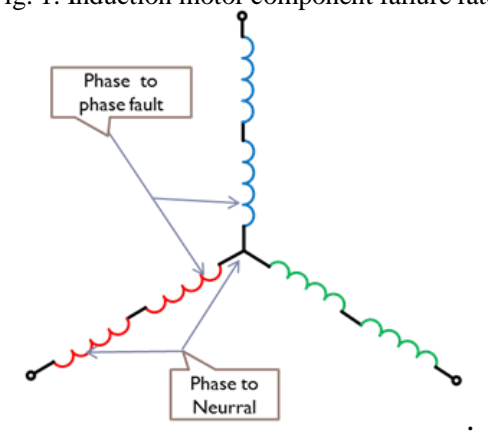

Fig. 2. Two different types of stator winding failures.

Stator winding faults are caused by multiple reasons such as vibration due to electromechanical force, high voltage surges, overload thermal condition and contamination [9],[12]. In this circumstance, the degradation of insulators in stator windings will happen during the machine operation. If the winding are short-circuited, a large circulating current is generated and gives rise to hotspots inside the machines. The excessive heat deteriorates the insulation and may cause phase to phase or phase to ground short circuits, as shown in Fig. 1. If left untreated, faults can propagate and may lead to the system breakdown. Therefore, this paper is aimed at detecting the stator windings failures in induction machines.

\section{B. Stray Flux Detection Technologies}

More recently, condition monitoring technologies based on stray magnetic field analysis has been developed. The stray flux is a magnetic flux that radiates from the inside of the machine frame and is strictly connected to the magnetic state of the machines. The stray flux is generated by the stator and rotor currents with different spectral components. A major advantage of this method is its non-invasive measurement and simply implementation. Comparing with the winding current signature analysis, stray flux analysis is much more sensitive, robust and reliable, thus is suited for initial fault detection for induction machine [13]. Moreover, its results include rich information such as the location of defects in induction machine. However, current diagnostic systems can not discriminate between different faults since they are influenced by distortions in power supply and dynamic load [14].

At the early stage of flux measurement technologies, search coils are installed at the end windings of the machine around the shaft. In this case, axil flux leakage of machine can be detected. More specifically, by analyzing these flux signals in frequency domain, different kinds of defects can be found. [15],[16] show results for radial magnetic field with a search coil positioned in the vicinity of an induction machine. In recent years, researchers develop new magnetic flux detection devices to increase sensitivity and accuracy of condition monitoring systems. A "C-shape" flux probe is developed in [7], which can be installed for different machine sizes. Nonetheless, these search coils are based on Faraday's Law of Induction and can not measure static magnetic field [5]. Additionally, existing commercial search coils have low sensitivity and accuracy, since they are dictated by the permeability of the iron core, and numbers of coil turns. Their resolution and bandwidth are not suitable for low flux measurements.

With the advent of new GMR sensors, static flux and point measurements become possible and are extremely useful for condition monitoring. Besides, they have very high resolution and sensitivity. GMR sensors have been applied to nondestructive testing and evaluation for ferromagnetic or electrical conductive materials. Their have proven advantages of high sensitivity and spatial resolution, linearity and frequency responses to magnetic fields [17]. For example, they can detect cracks within micro conductors in combination with an eddy-current method [18], and micro-solder-balls grid arrays on planar surfaces of printed circuit boards [17]. They have a wide field of application for inspection of different depth and orientation of the crack in plates, bearings and rails. As a result, GMR sensor arrays are adopted in induction machines in this work.

\section{SimULATION OF STATOR WINDING FAILURES IN INDCUTION MACHINES}

In order to understand stray magnetic flux, a finite element (FE) model has been built to investigate the potential influence of stator winding faults in induction machines. Then, the specifications of GMR sensors and sensor installation positions can be determined. 


\section{A. Finite Element Model}

A three-phase induction machine is firstly modeled and built in the finite element software where the same induction machine will be later tested in the experimental test rig. The specifications of the induction machine are shown in Table I. Furthermore, electromagnetic field distribution with healthy state and winding failure are analyzed as well.

\begin{tabular}{|l|c|}
\hline \multicolumn{1}{|c|}{ Item } & Value \\
\hline Rate power & $1.5 \mathrm{~kW}$ \\
\hline Pole number & 4 \\
\hline Phase number & 3 \\
\hline Rated stator current & $7 \mathrm{~A}$ \\
\hline Rated stator voltage & $220 \mathrm{~V}$ \\
\hline Rated speed & $1460 \mathrm{rpm}$ \\
\hline Stator slot & 36 \\
\hline Rotor slot & 28 \\
\hline Outer diameter of stator & $140 \mathrm{~mm}$ \\
\hline Inner diameter of stator & $88 \mathrm{~mm}$ \\
\hline Air-gap length & $0.8 \mathrm{~mm}$ \\
\hline
\end{tabular}

TABLE I SPECFICATIONS OF THE INDUCTION MCHINE

\section{B. Numerical Results with Winding Faults}

1) Healthy state of magnetic flux field. In order to investigate the change in stray flux field, a steel housing and yoke is also built in the FE model. The magnetic flux distribution and stray flux under health state are calculated and illustrated in Figs. 3 and 4, respectively. In this context, the baseline information of stray flux can be observed in healthy state and also helps to determine the specifications of magnetic sensors.

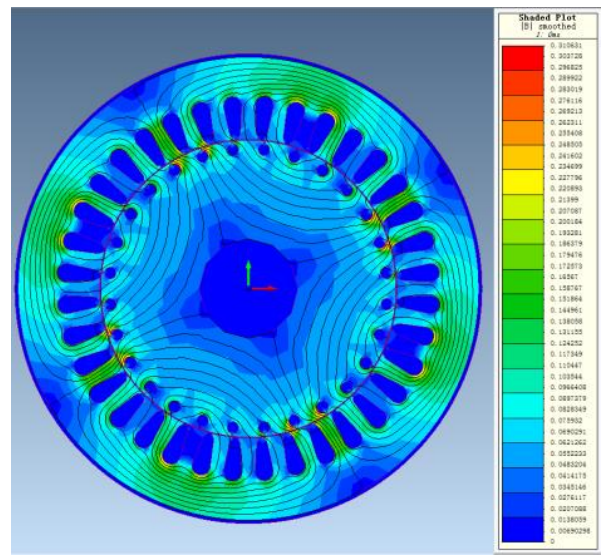

Fig. 3. Magnetic flux distributions of FE model.

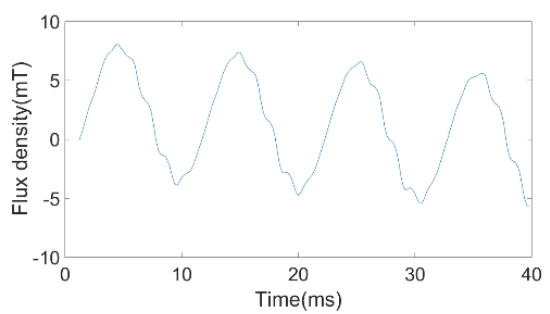

Fig. 4. Stray flux density at induction machine housing.

2) Phase to phase short circuit simulation. By changing the connections and winding parameters, a phase to phase short circuit is formed and simulated in the FE model. As the circuit current creates an unbalance inside the induction machine, the magnetic field and stray flux distribution are different from healthy states, as shown in Fig. 5.

Once a winding fault occurs inside an induction machine, three-phase currents become unbalanced so as to distort the magnetic flux and stray flux. Stray flux results at the same detection point are shown in Fig. 6.

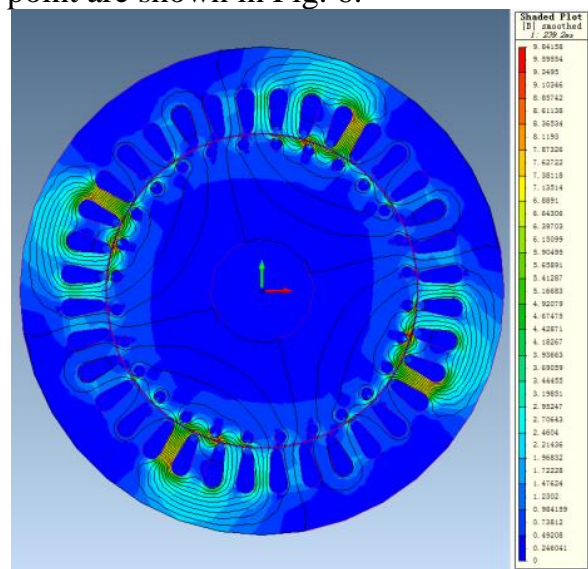

Fig. 5. Magnetic flux distribution with a phase to phase fault.

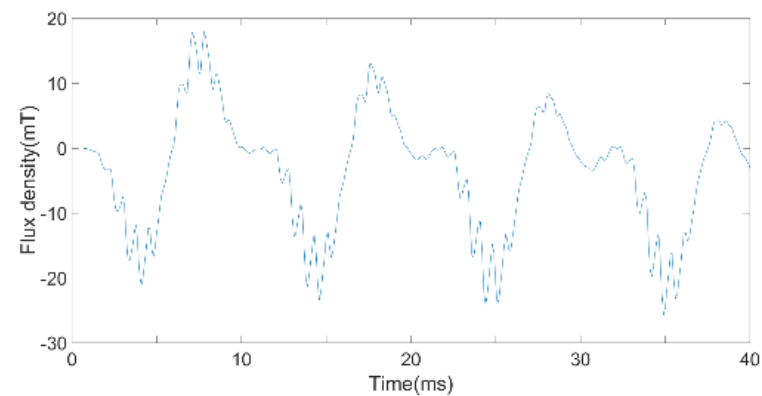

Fig. 6. Stray magnetic flux with a stator winding fault.

\section{EXPERIMENTAL VILAIDATION}

\section{A. Experiment test bench set up}

An experiment test rig has been set up to validate the proposed technology, as shown in Fig. 7. The test machine is a four pole three phase induction machine with a steel housing and frame. The stator windings are star-connected and the rotor is short-circuited. The machine is controlled by a converter via a Labview interface in the control PC. A DC motor is coupled to the test machine as the load. The GMR sensor is installed at the middle of the housing to capture the leaked stray flux. The output signal of magnetic sensors is collected by a NI data acquisition card with a $5-\mathrm{kHz}$ sampling frequency. By changing the wire connection at the fault point, different stator winding faults can be emulated and tested in the experiment test rig, including phase to phase and phase to neutral short-circuits.

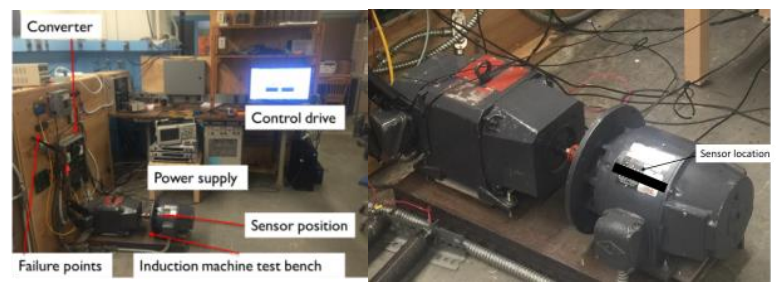

Fig. 7. Experimental test rig 
From the simulation results, the stray magnetic flux density is within a level to be detected. In this case, the specifications of detect sensors and sensor arrays are designed to capture the magnetic flux escaping from machine housing. GMR sensor arrays can meet the design requirement and have good performance at low magnetic fields. After collecting stray flux data, the results be compared between different healthy states in both time and frequency domains.

\section{B. Experiment Results}

The stator winding fault test is to detect stray flux field variations during different situations. The stray flux is measured in radial direction of the machine housing when the test machine is running at steady state. To build the healthy baseline information of stray flux, GMR sensors firstly capture the stray flux of the healthy machine with different output voltages from the converter. The line to neutral voltages are set at $10 \mathrm{~V}, 90 \mathrm{~V}, 70 \mathrm{~V}, 40 \mathrm{~V}$ and $20 \mathrm{~V}$. The output signals of GMR sensors are presented in Fig. 8.

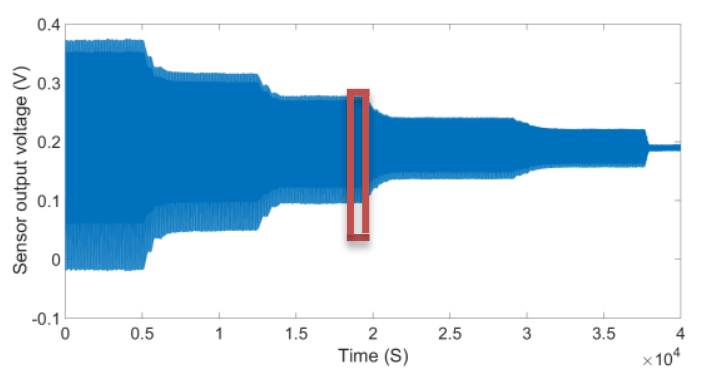

a) Stray flux data at different voltage outputs

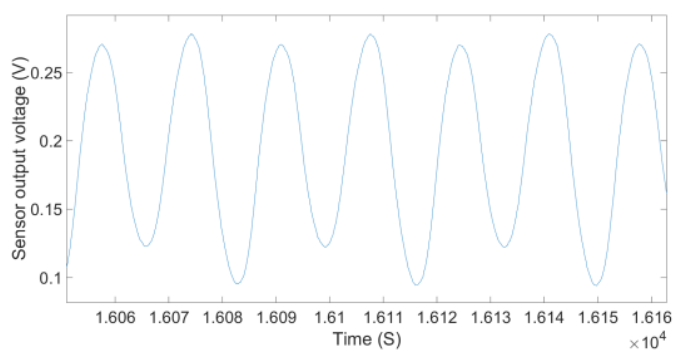

b) Stray flux data at $70 \mathrm{~V}$

Fig. 8. Stray flux baselines for the healthy induction machine.

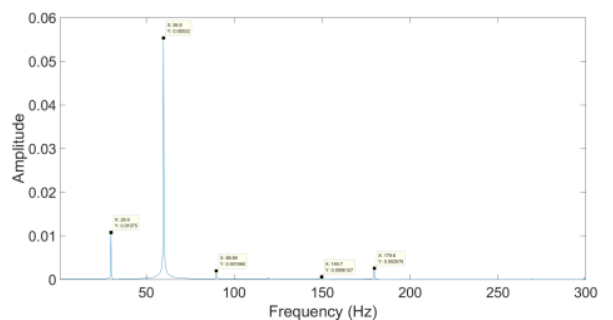

Fig. 9. Stray flux spectrum of the healthy induction machine.

In theory, the stray flux in the radial direction is created by both stator and rotor currents. More specifically, current flow in the stator windings generates the main air-gap flux. Due to the attenuation phenomena of the stator lamination and machine housing, the stray flux can be seen as a reduced air-gap flux. The attenuation can be decoupled and presented as a global transmission coefficient which links the two together.

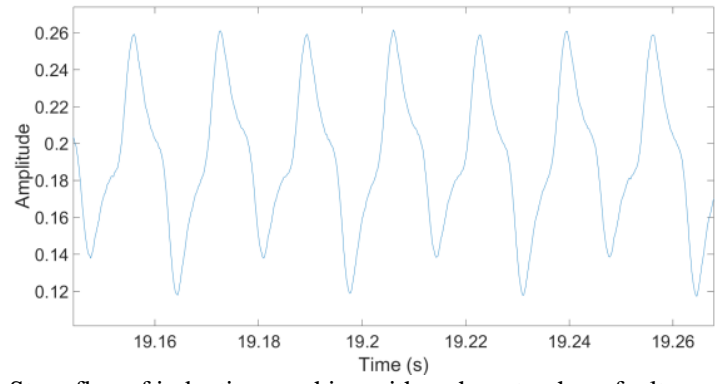

Fig. 10. Stray flux of induction machine with a phase to phase fault.

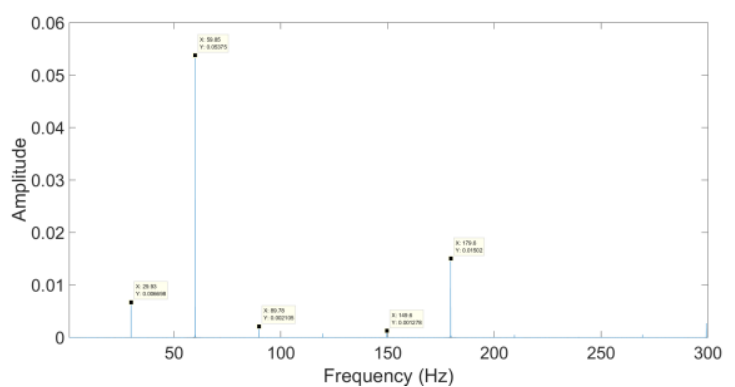

Fig. 11. Stray flux spectrum of induction machine with phase to phase failure

Fig. 9 provides the stray flux spectrum of the healthy induction machine. The different frequency components reflect the characteristics of the test machine. The fundamental frequency is $60 \mathrm{~Hz}$, and there are several harmonic components, which are influenced by slotting effect and geometry of the machine. With the influence of eddy currents in the housing, there is also a slight difference between simulation and experiment results.

By created a phase to phase winding fault, the stray flux of the test machine changes, as shown in Fig. 10. As a short circuit occurs in the stator windings, the current flowing in the faulted phase is increased. Therefore, the induction machine becomes unbalanced which is shown in the stray flux results.

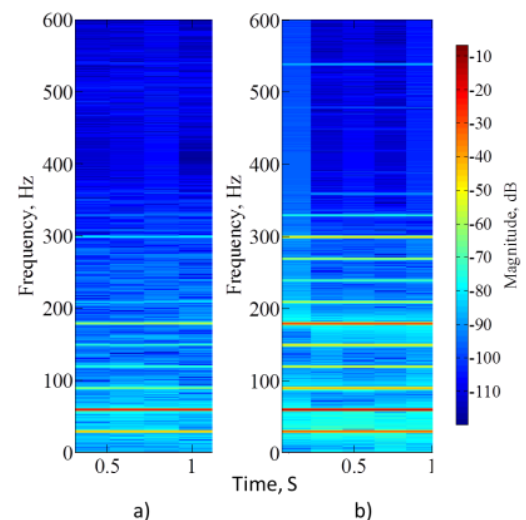

Fig. 12. a) STFT spectrogram of stray flux with healthy induction machine b) STFT spectrogram of stray flux with phase to phase failure

By apply the Fast Fourier Transform (FFT) analysis, the stray flux signal can be observed in frequency domain. Fig. 11 shows the stray flux spectrum of induction with the phase to phase short circuit. Compared with the healthy state (Fig 9), the amplitude of several harmonic components has already changed. The 3rd harmonic $(180 \mathrm{~Hz})$ is increased by about 6 times from 0.002575 to 0.01502 . Additionally, the $150-\mathrm{Hz}$ 
harmonic is also doubled. However, the fundamental component and its side band keep at the same level as the normal state. From the stator current signature analysis, the $3^{\text {rd }}$ harmonic component is also proven to be useful to identify an unbalance and winding faults. As a result, the $3^{\text {rd }}$ harmonic component is used as an indicator for phase to phase winding short circuits in induction machines.

By applying short-time Fourier transform (STFT) to the stray flux data, the time-frequency spectrograms are shown in Fig 12 under different states of the tested induction machine. The harmonic pattern information can be observed based on these two spectrograms. Comparison with FFT results, $3^{\text {rd }}$ harmonic is also increased from $-53.83 \mathrm{~dB}$ to $-27.98 \mathrm{~dB}$. Additionally, between $200 \mathrm{~Hz}$ to $300 \mathrm{~Hz}$, there are several harmonics raised in Fig $12 \mathrm{~b}$, which are $210 \mathrm{~Hz}, 239.3 \mathrm{~Hz}$ and $269.8 \mathrm{~Hz}$, which are difficult to find in FFT results. Spectrograms can not only provide tiny abnormal of frequency component but also combine time information together.

\section{CONCLUSION AND FUTURE WORK}

In this paper, a new non-invasive condition monitoring method for induction machines has been proposed. It measures the stray magnetic flux field outside of the machine frame using GMR magnetic sensors. The proposed method offers a low-cost stray flux measurement with wide range spectrum response, and high resolution of low-level magnetic field detection.

Simulation results from different stator winding short circuits can aid in the arrangement of GMR sensors and arrays for specific test requirements. Experimental results have confirmed that the proposed condition monitoring system is capable of capturing stray magnetic flux even though the leaking flux signal is quite weak. By studying the measured stray flux in time domain and especially in frequency domain, several significant harmonic components can be used as the indicators of stator winding faults. The time-frequency spectrogram can provide better harmonic patterns and information comparing with frequency spectrum.

The developed system is inexpensive and small in size. However, the effect of the eddy current in the housing and the yoke on the measured stray flux is unknown. In the further work, the signal processing and reconstruction will be applied to the result analysis so as to remove it from test results.

\section{REFERENCES}

[1] W. Cao and K. J. Bradley, "Assessing the impacts of rewind and repeated rewinds on induction motors: is an opportunity for Re-designing the machine being wasted?" IEEE Transactions on Industry Applications, Vol. 42, No. 4, pp. 958-964, Jul./Aug. 2006.

[2] M. El Hachemi Benbouzid, "A review of induction motors signature analysis as a medium for faults detection," IEEE Transactions on Industrial Electronics, Vol. 47, No. 5, pp. 984993, Oct. 2000.
[3] W. T. Thomson and M. Fenger, "Current signature analysis to detect induction motor faults," IEEE Industry Applications Magazine, Vol. 7, No. 4, pp. 26-34, 2001.

[4] L. Frosini, C. Harlisca, and L. Szabó, "Induction machine bearing faults detection by means of statistical processing of the stray flux measurement," IEEE Transactions on Industrial Electronics, Vol. 62, No. 3, pp. 1846-1854, March 2015.

[5] M. Riera-Guasp, J. Antonino-Daviu, and G. Capolino, "Advances in electrical machine, power electronic and drive condition monitoring and fault detection: state of the art," IEEE Transactions on Industrial Electronics, Vol. 62, No. 3, pp. 1746-1759, March 2015.

[6] H. Henao, C. Demian, and G. A. Capolino, "A frequencydomain detection of stator winding faults in induction machines using an external flux sensor," IEEE Transactions on Industry Applications, Vol. 39, No. 5, pp. 1272-1279, 2003.

[7] L. Frosini, A. Borin, L. Girometta, and G. Venchi, "A novel approach to detect short circuits in low voltage induction motor by stray flux measurement," XXth International Conference on Electrical Machines (ICEM), pp. 1538-1544, 2012.

[8] D. G. Dorrell, W. T. Thomson, and S. Roach, "Analysis of airgap flux, current, and vibration signals as a function of the combination of static and dynamic airgap eccentricity in 3phase induction motors," IEEE Transactions on Industry Applications, Vol. 33, No. 1, pp. 24-34, Jan./Feb. 1997.

[9] A. H. Bonnett and G. C. Soukup, "Cause and analysis of stator and rotor failures in 3-phase squirrel cage induction motors," Annual Pulp and Paper Industry Technical Conference, pp. 2242, 1991.

[10] O. V. Thorsen and M. Dalva, "A survey of faults on induction motors in offshore oil industry, petrochemical industry, gas terminals and oil refineries," 41st Annual Petroleum and Chemical Industry Conference, pp. 1-9, 1994.

[11] M. E. H. Benbouzid and G. B. Kliman, "What stator current processing-based technique to use for induction motor rotor faults diagnosis?" IEEE Transactions on Energy Conversion, Vol. 18, No. 2, pp. 238-244, Jun. 2003.

[12] J. Seshadrinath, B. Singh, and B. K. Panigrahi, "Incipient turn fault detection and condition monitoring of induction machine using analytical wavelet transform," IEEE Transactions on Industry Applications, Vol. 50, No. 3, pp. 2235-2242, May/Jun. 2014.

[13] A. Ceban, R. Pusca, and R. Romary, "Study of rotor faults in induction motors using external magnetic field analysis," IEEE Transactions on Industrial Electronics, Vol. 59, No. 5, pp. 2082-2093, May 2012.

[14] P. C. M. Lamim Filho, R. Pederiva, and J. N. Brito, "Detection of stator winding faults in induction machines using flux and vibration analysis," Mechanical Systems and Signal Processing, Vol. 42, Issues 1-2, pp. 377-387, Jan. 2014.

[15] M. D. Negrea, "Electromagnetic flux monitoring for detecting faults in electrical machines," Ph.D. dissertation, Dept. Elect. Eng, Helsinki University of Technology, Finland, 2006.

[16] V. Kokko, "Condition monitoring of squirrel-cage motors by axial magnetic flux measurements," Ph.D. dissertation, Dept. Elect. Eng, University of Oulu, Oulu, Finland, 2003.

[17] J. W. Wilson, G. Y. Tian, and S. Barrans, "Residual magnetic field sensing for stress measurement," Sensors and Actuators A: Physical, Vol. 135, pp. 381-387, 2007. 
[18] J. W. Wilson and G. Y. Tian, "Pulsed electromagnetic methods for defect detection and characterisation," NDT \& E International, Vol. 40, pp. 275-283, 2007. 